\title{
BENEFICIUM COMPETENTIAE DO SÓCIO (SOCIUS)
}

\author{
Ignácio Maria Poveda Velasco \\ Professor Doutor do Departamento de Direito Civil da Faculdade de \\ Direito da Universidade de São Paulo
}

\begin{abstract}
Resumo:
O beneficium competentiae em favor do sócio pode ser reconstituído da seguinte forma: após a introdução nos começos do séc. II a. C. da actio pro socio no edito do pretor urbano, a condenação limitada em favor do sócio omnium bonorum, concedida pelo pretor causa cognita, teria sido introduzida em cláusula especial, provavelmente em fins do séc. II a. C. ou nas primeiras décadas do séc. I a. C. Razão de ser deste tratamento diferenciado em favor do sócio universal, sua ratio, teria sido a existência de um vínculo de especial confiança, originando um ius quodammodo fraternitatis. Parece, porém, razoável admitir que desde o fim da República ou começo do Império alguns jurisconsultos defendessem a aplicação extensiva do benefício aos demais tipos de sociedade, chegando o assunto a motivar discussão entre eles.
\end{abstract}

\begin{abstract}
:
The beneficium competentiae in favor of the partner can be constituted by the following way: after the introduction in the beginning of century II a.C. of actio pro socio in the edit from the urban praetor, the condemnation limited in favor of the partner omnium bonorum, given by the praetor causa cognita, would have been introduced in special clause, probably at the end of the II Century a. C. or in the first decades of the century I a. C. The reason of this differentiated treatment in favor of the universal partner, your ratio, would have been the existence of an especial link of trustiness, creating an ius quodammodo fraternitatis. It seems, however, reasonable to admit that since the end of the Republic or in the beginning of Empire, some jurisconsults defended the extensive application of the benefit to the other types of society, with this topic promoting the discussion among them.
\end{abstract}

Unitermos: beneficium competetiae; actio pro socio; socio omnium bonorum.

A condenação limitada concedida ao socius foi introduzida pelo direito honorário, conforme se deduz do seguinte texto de Pompônio:

Pomp. 21 ad Q. Muc., D. 42, 1, 22, 1: Quod autem de sociis dictum est, ut et hi in quantum facere possint condemnentur, causa cognita se facturum 
praetor edicit, causae cognitio autem in hoc erit, ut neganti se socium esse aut ex doli clausula obligato non succurratur.

[O dito a respeito dos sócios, a saber, que também eles sejam condenados até onde possam pagar, isto o pretor, no seu edito, declara que o fará com prévio conhecimento de causa, a fim de não socorrer a quem negue ser sócio ou tenha se obrigado por uma cláusula de dolo].

$\mathrm{Na}$ opinião de Guarino,' talvez seja este o mais antigo dentre os diversos casos de condenação limitada que aparecem nas fontes, podendo ter servido de modelo aos demais.

Várias são as questões suscitadas pela condenação limitada do sócio. A primeira, relativa ao momento do seu aparecimento: o beneficium competentiae do sócio existe desde o surgimento da societas consensual e a correspondente actio pro socio, ou é posterior a elas? A segunda, a respeito da espécie de sócio beneficiado: quem gozaria da condenação limitada, todo e qualquer sócio ou apenas o da societas omnium bonorum? Finalmente, com relação às circunstâncias em que se dá a concessão do benefício: existem pré-requisitos ou aspectos limitantes? Quais?

Antes, porém, de proceder à análise destas questões, parece-nos necessário fazer alguns esclarecimentos relativos à societas e à ação que a tutela.

A societas romana é o contrato consensual, bilateral ou plurilateral, em virtude do qual duas ou mais pessoas (socii) se obrigam a desenvolver em comum uma determinada atividade e a contribuir para ela com bens (res) ou serviços (operae), visando um fim determinado e dividindo lucros e perdas. ${ }^{2}$

É incerta a origem da sociedade consensual no Direito Romano. É discutida, também, a evolução do instituto e o modo como foram surgindo as diversas espécies de sociedade. ${ }^{3}$

1. Cf. Guarino, La condanna nei limiti del possibile, 2. ed., Napoli, Jovene, 1978, p. 25.

2. Cf. Arangio-Ruiz, La società in diritto romano, Napoli, Jovene, 1982, pp. 29 e ss.; Talamanca, Istituzioni di diritto romano, Milano, Giuffrè, 1990, p. 598; e Girard, Manuel élémentaire de droit romain, 8.ed., Paris, Arthur Rousseau, 1929, p. 611.

3. Basicamente, são quatro as espécies de sociedade: a. a societas omnium bonorum, na que se estabelece co-propriedade de todos os bens presentes e futuros dos sócios, tendo em vista a consecução de um fim patrimonial comum; b. a societas universorum (ou omnium) quae ex quaestu veniunt, na qual os sócios põem em comum apenas o produto de seu trabalho e o rendimento de seus bens, excluindo da sociedade os bens presente e os futuros adquiridos a título gratuito; c. a societas unius negotiationis ou unius rei, tendo em vista a realização de uma única operação ou o compartilhamento de um único bem (um imóvel, um escravo, etc.); e d. a societas alicuius negotiationis, em face da qual os sócios se propõem a realização de uma série de operações comuns, de natureza comercial ou 
Há quem sustente que os vários tipos de societates têm origens diversas. ${ }^{4}$ a societas omnium bonorum derivaria do consortium ercto non cito $^{5}$; a omnium quae ex quaestu veniunt e a societas alicuius negotiationis, de associações comerciais decorrentes de preexistentes experiências romanas (como as societas publicanorum); e a societas unius rei da politio, instituto do velho ius civile, no qual o proprietário de um imóvel se associava com um agricultor perito -politor-para melhorar o rendimento de suas terras, oferecendo-lhe participação nos lucros. ${ }^{6}$

A communis opinio, contudo, entende que a societas nada mais é que a transposição em termos simplificados e aberta à participação de peregrini, do velho consortium ercto non cito, originando a societas omnium bonorum. Desta última teriam derivado as demais espécies de sociedade. ${ }^{7}$

Levet observa que a origem da sociedade de todos os bens ou universal remonta à época antiga, àquelas sociedades familiares formadas pelos irmãos após a morte do paterfamilias, as quais não tinham no interesse especulativo sua principal razão de ser. Embora, posteriormente, muitas sociedades universais se constituíssem sem a existência desse caráter familiar, permaneceu nelas uma relação de especial confiança (fiducia, comportando um ius quodammodo fraternitatis.). ${ }^{8}$

Segundo Arangio-Ruiz, ${ }^{9}$ o reconhecimento da societas como contrato consensual se dá, em primeiro lugar, nas relações entre cidadãos romanos e

industrial. Cf. Girard, Manuel élémentaire..., cit. (nota 2), pp. 611-2; e Moreira Alves, Direito Romano, v. 2, 4. ed., Rio de Janeiro, Forense, 1986, p. 206.

4. Assim, Talamanca, Istituzioni..., cit. (nota 2), p. 597. Cf., também, a exposição de Guarino, Diritto privato romano, 8.ed., Napoli, Jovene, 1988, p. 814 e a de Moreira Alves, Direito Romano..., cit. (nota 3), v.2, pp. 206-7.

5. Ver, a respeito, Arangio-Ruiz, La società..., cit. (nota 2), pp. 3-22. Cf., também, Marky, Sociedade "ercto non cito" in Romanitas: Revista de Cultura Romana, Rio de Janeiro, v. 1, n. 1, 1958, pp. 40-60.

6. É este contrato agrário, referido por Catão (de agri cultura 136 e 137 [145 e 146]), o tipo mais antigo de sociedade não-universal que se conhece em Roma. $\mathrm{O}$ acordo do qual surge a sociedade para cultivo de um terreno (chamado contrato de politio - cf. Ulp. 31 ed., D. 17, 2, 52, 2) se aproxima, na opinião de D'Ors, Derecho privado romano, 5. ed., Pamplona, Eunsa, 1983, p. 547, nota 6, do arrendamento.

7. Nesse sentido, Arangio-Ruiz, La società..., cit. (nota 2), p. 19; e Girard, Manuel élémentaire..., cit. (nota 2), p. 611. Ver, ainda, a exposição de Guarino sobre o assunto in Diritto privato..., cit. (nota 4), p. 814.

8. Cf. Le bénéfice de compétence, Paris, Recueil Sirey, 1927, p. 48. Ver, nesse sentido, Ulp. 31 ed., D. 17, 2, 63 pr.

9. Cf. La società..., cit. (nota 2), p. 29. 
estrangeiros, discutidas perante o tribunal do pretor peregrino. $\mathrm{Na}$ opinião de Guarino, ${ }^{10}$ isto deve ter acontecido a partir da segunda metade do séc. III a. C., época do início da grande expansão comercial romana pelo Mediterrâneo.

É razoável afirmar que a sociedade consensual tenha surgido no direito pretoriano. Aliás, o fenômeno da criação honorária de institutos em virtude de regras do ius gentium é bastante freqüente. ${ }^{11}$

A sociedade universal, derivando do velho consortium ercto non cito, observava as regras deste para efeitos de sua constituição, particularmente a prática da in iure cessio, através da qual se dava a transferência de propriedade dos bens dos sócios, necessária ao estabelecimento do condomínio entre eles. Isto, porém, só e apenas se constituída entre cives; nesse caso seria o ius civile a regular e dirimir as diferenças entre eles. Mas, e se um cidadão romano resolvesse estabelecer uma sociedade universal com um estrangeiro naqueles idos do início do séc. II a. C.? Não existindo a possibilidade de praticar as formalidades do ius civile, restava, apenas, o acordo de vontades como elemento constitutivo da sociedade. Foi fazendo desse consentimento mútuo o elemento essencial do contrato que o pretor peregrino criou a societas consensual, inicialmente como sociedade de todos os bens.

Guarino $^{12}$ supõe que, pouco tempo depois, mas ainda nas primeiras décadas do séc. II a. C., a societas consensual tenha sido também reconhecida entre cidadãos romanos, passando a figurar no edito do pretor urbano junto com a fórmula da actio pro socio, criada especialmente para dirimir possíveis desavenças entre os sócios.

A reconstituição provável da fórmula desta ação é feita por Lenel ${ }^{13}$ nos seguintes termos:

Quod $A^{S} A^{S}$ cum $N^{O} N^{o}$ societatem omnium bonorum coiit, q. d. r. a., quidquid ob eam rem $N^{m} N^{m} A^{o} A^{o}$ (alterum alteri) dare facere (praestare?)

10. Cf. La condanna..., cit. (nota 1), p. 30.

11. A mesma origem têm a compra e venda, a locação e o mandato, não tanto pelo que se refere ao seu conteúdo econômico mas pelo que diz respeito à sua estrutura contratual e, particularmente, à agilidade própria dos contratos consensuais. Cf., nesse sentido, Arangio-Ruiz, La società..., cit. (nota 2), p. 28.

12. Cf. La condanna..., cit. (nota 1), p. 30.

13. Cf. Das Edictum perpetuum (ein Versuch zu seiner Wiederherstellung), $2^{\mathbf{a}}$ reimpr. da 3. ed., Leipzig, 1927. Aalen, Scientia, 1974, p. 297. 
oportet ex fide bona, dumtaxat quod $N^{S} N^{S}$ facere potest, eius iudex $N^{m} N^{m} A^{O} A^{O} c$. s. n. p. a. ${ }^{14}$

[Tendo Aulo Agélio entrado em sociedade universal com Numério Negídio, que Numério Negídio, somente até onde puder pagar, seja condenado em boa-fé a dar, fazer ou prestar em favor de Aulo Agélio; se não parecer, que Numério Negídio seja absolvido].

Lenel, ${ }^{15}$ ao incluir em sua reconstituição da fórmula edital a referência à societas omnium bonorum, dá a entender que era esta a espécie de sociedade originariamente protegida pela actio pro socio.

Arangio-Ruiz ${ }^{16}$ compartilha desta opinião. Discorda, porém, da redação oferecida por Lenel. Na sua opinião, o texto original da fórmula não fazia referência expressa à sociedade universal ou a qualquer outro tipo de sociedade, falando apenas em societas.

Para o romanista italiano, foi a sociedade universal, reminiscência do antigo consortium ercto non cito, que os primeiros tratadistas do ius civile tiveram em vista ao elaborarem seus tratados científico-práticos e a que, sob a sua orientação, serviu de base para a elaboração pelo pretor da fórmula da actio pro socio. ${ }^{17}$ A referência à societas omnium bonorum seria tão-evidente a ponto de dispensar sua menção expressa no texto da fórmula. $\mathrm{E}$, conclui dizendo que prova disto seria o fato de os comentários ao Edito, na parte relativa à fórmula da actio pro socio, tomarem sempre a sociedade universal como ponto de partida. ${ }^{18}$

14. Transcrevemos a redação oferecida por Arangio-Ruiz, La società..., cit. (nota 2), p. 30, a qual, ao colocar por extenso as abreviações do texto de Lenel, o torna mais inteligível: Quod Aulus Agerius cum Numerio Negidio societatem omnium bonorum coilt, qua de re agitur, quidquid ob eam rem Numerium Negidium Aulo Agerio dare facere oportet ex fide bona, <dumtaxat quod Numerius Negidius facere potest $>$, eius iudex Numerium Negidiun Aulo Agerio condemnatur: si non paret, absolvito.

15. Cf. Das Edictum ..., cit. (nota 13), pp. 298-9.

16. Cf. La società..., cit. (nota 2), p. 31.

17. Cf. La società..., cit. (nota 2), p. 29.

18. No mesmo sentido, Lenel, Das Edictum..., cit. (nota 13), p. 297, nota 8, menciona os comentários recolhidos nos seguintes fragmentos: Paul. 32 ed., D. 17, 2, 1, 1, e D. 17, 2, 3, 1; Ulp. 31 ed., D. 17, 2, 5 pr. e Gai. 3, 148. Na p. 31, nota 2 do La società..., cit.(nota 2), Arangio-Ruiz refere-se a uma demonstração de Wieacker a respeito, minuciosa e incontestável, in Societas: Hausgemeinschaft und Enverbsgesellschaft (Untersuchungen zur Geschichte des römischen (iesellschafisrechts), 1, Weimar, 1936, pp. 243 e ss. 
Arangio-Ruiz observa ${ }^{19}$ que as fórmulas apresentavam um aspecto semelhante ao dos atuais formulários e traziam, junto a termos considerados essenciais, espaços em branco equivalentes aos nossos pontilhados modernos, para serem preenchidos com os dados particulares do caso. Era comum, diz ele, que o pretor, para exemplificar, apresentasse a fórmula preenchida com elementos fictícios referentes aos nomes, ao montante da dívida, etc. Esses elementos ganharam da romanística germânica a denominação de «Blankettworte», expressão que designa as palavras colocadas no lugar dos espaços em branco.

Para Arangio-Ruiz, tal prática tem dificultado, por vezes, distinguir as palavras que o pretor introduzia no texto à guisa de exemplo (as referidas «Blankettworte»), daquelas outras que, pelo contrário, faziam parte do conteúdo da ação como seu pressuposto essencial e imutável, induzindo o estudioso a erro. Para o mestre italiano, neste engano teria incorrido Lenel, ao incluir na sua reconstituição a referência à societas omnium bonorum como se de parte essencial da fórmula se tratasse, quando apenas era uma «Blankettworte».

Embora originariamente a actio pro socio fosse criada visando a sociedade universal, é certo que, no decorrer do tempo, terminou ela servindo para dirimir conflitos decorrentes de todo e qualquer tipo de sociedade consensual.

Passemos, agora, à análise da condenação limitada. Teria sido ela introduzida junto com a actio pro socio, como parte constitutiva da fórmula desta, ou devemos considerá-la criação posterior?

Guarino $^{20}$ entende que o aparecimento da condenação in id quod debitor facere potest, é posterior à criação da actio pro socio. Em sua opinião não é compreensível que numa época de grande florescimento comercial, como a das primeiras décadas do séc. II a. C., já apontada como a do provável momento da introdução da ação do sócio, as alianças comerciais dos agentes econômicos (pois tais eram em substância, as sociedades baseadas no nudus consensus e na confiança recíproca) pudessem se constituir sob a ameaça permanente de uma possível condenação limitada ao id quod debitor facere potest. Sendo, de resto, a actio pro socio uma actio famosa, a simples possibilidade de vir a sofrer a infamia bastaria para obrigar o sócio a pensar bem as coisas antes de se decidir por assumir um compromisso social e, na constância do mesmo, ter todo o cuidado para não ocasionar prejuízos ao outro sócio.

19. Cf. La società..., cit. (nota 2), p. 29, nota 4.

20. Cf. La condanna..., cit.(nota 1), pp. 30-31. 
A condemnatio in id quod facere potest se ambienta, para Guarino, num momento de depressão econômica e de insegurança do comércio, tal como aquele dos últimos anos do séc. II a. C. e, principalmente, de boa parte do séc. I a. C., época durante a qual a possibilidade de obter a vantagem de uma condenação limitada teria aliviado a situação de muitos sócios em apuros. Nesses tempos de lutas civis, constituir uma sociedade, diz Guarino, ${ }^{21}$ era como embarcar juntos numa aventura comum, "affratelarsi", diz ele, irmanar-se num risco comum. ${ }^{22}$

Embora não se manifeste expressamente sobre o momento do aparecimento da condenação limitada, Lenel, ao introduzir na fórmula da actio pro socio as palavras do benefício (dumtaxat quod $N^{s} N^{s}$ facere potest) dá a entender que $o$ considera coetâneo daquela. ${ }^{23}$

Arangio-Ruiz também não se manifesta sobre o momento da introdução da condenação in id quod facere potest. Limita-se a transcrever a fórmula reconstituída por Lenel, dela excluindo, porém, o benefício da condenação limitada $^{24}$ objeto em sua opinião de cláusula à parte. ${ }^{25}$

\section{Cf. La condanna..., cit.(nota 1), p. 31.}

22. Daí o ius quodammodo fraternitatis mencionado em Ulp. 31 ed., D. 17, 2, 63 pr., (ver supra nota 8), texto que será examinado logo adiante.

23. Na primeira edição de sua obra, publicada em 1883, Lenel reconstitui a fórmula da actio pro socio inserindo nela a condenação limitada. Contudo, na tradução francesa dessa primeira edição [Essai de reconstitution de L'Edit Perpétuel, 2 v., (ouvrage traduit en français par Frédéric Peltier, sur un texte revu par l'auteur), Paris, Larose \& Forcel, 1901/1903], Lenel introduz, como ele próprio esclarece num prefácio ad hoc, algumas modificações de conteúdo, dentre elas a supressão da condenação limitada no texto da fórmula. Às pp.12/13 do v. 2, Lenel afirma que, como o pretor prometia somente causa cognita a introdução da condenação limitada na fómula (e faz referência ao texto de Pompônio, 21 ad Q. Muc., D. 42, 1, 22, 1), não se pode admitir que a cláusula «quod facere potest» figurasse na fórmula-tipo do Album (na nota 1 ele esclarece que esta orientação é contrária à da edição alemã). E, a seguir, complementa dizendo que se Ulpiano se ocupou dessa cláusula em 31 ed., D. 17, 2, 63, pr.-7, imediatamente após tratar da fórmula, isto provém do fato de o próprio edito que a introduziu, inseri-la após ela, a modo de apêndice. Lenel termina arriscando uma reconstituição desse apêndice, nestes termos: «Si iusta causa esse videbitur, hanc actionem dabo in id quod facere potest». Na segunda edição alemã de sua obra, publicada em 1907 (cf. Guarino, L'esegesi delle fonti del diritto romano, v.1, Napoli, Jovene, 1968, p.549, nota 116), Lenel volta atrás e afirma que, apesar da limitação da condenação ser concedida só caso a caso (causa cognita), deve-se imaginar que a cláusula «quod facere potest» figurasse na fórmula-tipo do Album. É esta, também, a posição do autor na terceira e definitiva edição alemã do "Edictum». "Diversamente, sem suficiente razão, éd. perp. II, 13" («Anders ohne zureichenden Grund éd. perp. II, 13»), são as palavras de Lenel na edição de 1907, reproduzidas, textualmente, na p.298, nota 4 da terceira edição. Não é claro para nós se ele diz ter mudado de opinião sem suficiente razão ou se julga que sua opinião anterior carecia da tal "suficiente razão". Seja como for, não encontramos, data venia, consistência argumentativa nesta última postura. Contudo, talvez Lenel tenha querido dizer que tanto a cláusula poderia estar inserida na fórmula quanto ter sido colocada em apêndice, questão esta que seria de menor importância.

24. Cf. La società..., cit. (nota 2), p. 30. 
Sintetizando a questão, parece-nos razoável concluir com Guarino, que a condenação limitada em favor do sócio tenha sido introduzida em época posterior à da criação da actio pro socio e que, seguindo a opinião de Arangio-Ruiz, o benefício integrasse cláusula à parte. $\mathrm{E}$ isto precisamente em virtude do argumento apresentado por Lenel na edição francesa do Edictum. ${ }^{26}$

Tendo a condenação in id quod facere potest sido inserida em cláusula anexa à fórmula da actio pro socio, cabe perguntar a que espécie de sócio ela beneficiaria. Seria apenas ao socius omnium bonorum ou também ao sócio de toda e qualquer sociedade?

A raiz da dúvida encontra-se na divergência entre dois textos do Digesto, ambos atribuídos a Ulpiano.

Lemos no primeiro:

Ulp. 31 ed., D. 17, 2, 63 pr.: Verum est quod Sabino videtur, etiansi non universorum bonorum socii sunt, sed unius rei, attamen in id quod facere possunt quodve dolo malo fecerint quo minus possint, condemnari oportere, hoc enim summam ratiomem habet, cum societas ius quodammodo fraternitatis in se habeat.

[É certo o que diz Sabino: que mesmo não sendo <os litigantes> sócios de todos os bens, mas de uma só coisa, devem, não-obstante, ser condenados na medida de suas posses ou do que teriam podido pagar se não tivessem agido com dolo. E isto é muito razoável se é verdade que a sociedade implica, como parece implicar, numa relação em certo modo de fraternidade.]

Por sua vez, o segundo declara:

Ulp. 63 ed., D. 42, 1, 16: Sunt qui in id quod facere possunt conveniuntur, id est non deducto aere alieno, et quidem sunt hi fere, qui pro socio conveniuntur (socium autem omnium bonorum accipiendum est)...

[Há os que são condenados no que possam pagar, ou seja, sem dedução de suas <outras> dívidas; e estes são, entre outros, os seguintes: os demandados pela ação dá sociedade (entenda-se, o sócio de todos os bens)...].

A doutrina divide-se ao indicar qual dos textos seria o original. Para uns, a orientação de Ulpiano, acompanhando a opinião de Sabino, seria conceder o benefício em todos os casos de sociedade, e nesse sentido o segundo texto (Ulp. 63 ed., D. $42,1,16)$ teria sido alterado por um intérprete pós-clássico. Para outros, a

25. Cf. La società..., cit. (nota 2), p. 184.

26. Cf. nota 23 supra. 
orientação original seria a restritiva e Justiniano, alterando o fragmento de Ulp. 31 ed., D. 17, 2, 63 pr., é que teria estendido a solução a toda e qualquer espécie de sociedade. A qual dos fragmentos supracitados dar crédito?

Num ponto todos os autores concordam, a saber, quando afirmam que, no direito justinianeu, o beneficium competentiae foi concedido ao sócio de toda e qualquer sociedade. $^{27}$

A questão é saber se a interpretação extensiva é obra do compilador ou se já no direito clássico, a começar por Sabino e depois com Ulpiano, o benefício tinha ampla aplicação.

Arangio-Ruiz ${ }^{28}$ afirma ser pacífica a referência originária do benefício ao caso da societas omnium bonorum. Assim sendo, esse tratamento privilegiado recebido pela sociedade universal talvez tivesse sua razão de ser, conforme Levet, ${ }^{29}$ naquela aproximação com as primitivas sociedades ercto non cito, nos estreitos vínculos de confiança que as caracterizavam e na ausência do interesse especulativo a que já fizemos referência. Pelo contrário, o intuito de lucro presente nas sociedades particulares, freqüentemente formadas por pessoas não-ligadas por vínculos de parentesco, teria sido o motivo de sua exclusão inicial do benefício.

Qual, porém, teria sido a orientação do direito clássico a este respeito? Aprofundemos a discussão tomando por base a argumentação de Guarino. ${ }^{30}$ Após analisar os dois fragmentos de Ulpiano, observa o autor que, sob o aspecto formal, ambos merecem reparos. Para ele, a parte final do primeiro fragmento (Ulp. $31 \mathrm{ed}$, D. 17, 2, 63 pr.: hoc enim summam rationem habet) é enfática demais para pertencer a Ulpiano.

No mesmo sentido de crítica formal à redação desse texto, Levet ${ }^{31}$ chama a atenção para a estranha construção que deixou de explicitar o sujeito do verbo condemnare oportet, e para o uso de termos com freqüência empregados pelos compiladores, como enim (geralmente utilizado para introduzir a interpolação), rationem e quodammodo.

27. Assim, Solazzi, L'estinzione della obbligazione, Napoli, Jovene, 1931, p. 207. O autor justifica sua posição observando que Ulp. $31 \mathrm{ed}$, D. 17, 2, 63 pr., que acolhe a aplicação extensiva do benefício, é o texto propositalmente situado pelo compilador no lugar próprio, ou seja, sob o título pro socio, o que confirmaria essa nova orientação.

28. Cf. La società..., cit. (nota 2), p. 31.

29 Cf. Le bénéfice..., cit. (nota 8), p. 50.

30. Cf. La condanna..., cit. (nota 1), pp. 27 e ss.

31 Cf. Le bénéfice..., cit. (nota 8), p. 56. 
Por outro lado, ainda segundo Guarino, o outro fragmento (Ulp. 63 $e d$. . D. $42,1,16)$ é claramente glosado por um leitor pós-clássico, pois a expressão «id est non deducto aere alieno», embora tenha significado concreto e exato do qual se falará oportunamente, ${ }^{32}$ encontra-se em lugar errado, dando a falsa impressão de que a limitação ao id quod debitor facere potest significava não levar em consideração o aes alienum. Guarino chama a atenção, ainda, para o período final deste texto (socium autem omnium bonorum accipiendum est), escrito, em sua opinião, num péssimo latim, de autoria de algum intérprete tardio que, tomando posição na controvérsia, teria alterado a orientação de Ulpiano. ${ }^{33}$ De resto, conclui Guarino, é significativa a injustificada passagem de um discurso no qual se fala de socii (no plural) para outro no qual se faz referência ao socius (no singular).

Passando à discussão do conteúdo dos fragmentos Guarino, ${ }^{34}$ partindo de Ulp. 31 ed., D. 17, 2, 63 pr., considera possível intuir uma discussão dos juristas anteriores a Sabino ( $1^{\mathrm{a}}$ metade do séc. I d. C.), a respeito da admissibilidade de concessão do benefício fora do caso da sociedade universal. Sabino ter-se-ia manifestado claramente a favor, inclusive até no caso oposto, o da societas unius rei, no que teria sido acompanhado por Ulpiano (séc. III d. C.).

Porém, diz Guarino, ${ }^{35}$ mais do que saber qual fosse a opinião de Sabino ou Ulpiano, o interessante é poder concluir, a partir do que estes textos apresentam, que no período clássico discutia-se se a limitação da condenação podia ser aplicada a todos os tipos de sociedade (omnium bonorum, omnium quae ex quaestu veniunt, unius negotiationis, unius rei, etc.), ou se, pelo contrário, devia ficar restrita apenas à societas universorum bonorum. Para concluir pela aplicação geral do benefício, diz Guarino, bastaria admitir que a cláusula edital sobre a

32. Trata-se da questão do facere posse, ou seja, da disponibilidade patrimonial do devedor. Para alguns o cálculo deveria ser feito com base no patrimônio bruto. Para outros, sobre o patrimônio líquido, ou seja, descontadas as dívidas (aes alienum) que o réu tivesse com credores outros, em relação aos quais não-gozasse do benefício.

33. Lenel, Das Edictum..., cit. (nota 13), p. 298, n. 7, também considera a frase um glossema, pela forma não-latina da mesma. No mesmo sentido, embora por via indireta de interpretação, pensa Arangio-Ruiz, La società..., cit. (nota 2), p. 30. Porém, para Levet, Le bénéfice..., cit. (nota 8), p.55, a afirmação que se faz de que o período «socium...accipiendum est» é errado, enquanto o certo deveria ser «socius...accipiendus est», não é suficiente para desautorizá-lo. Afinal, diz ele, as fontes tanto literárias quanto jurídicas oferecem numerosos exemplos de semelhante construção, nos quais o acusativo é empregado no lugar do nominativo. Por esta razão, Levet não hesita em considerar esta passagem como verdadeiramente de Ulpiano.

34. Cf. La condanna..., cit. (nota 1), p. 27.

35. Cf. La condanna..., cit. (nota 1), p. 29. 
condemnatio limitada falasse de socii em geral (sem qualquer especificação) e que, $a$ fortiori, a fórmula edital da actio pro socio não tivesse sido limitada ao caso da societas omnium bonorum.

Não é desta forma, contudo, que Lenel faz sua reconstituição: para ele a actio pro socio e a correspondente cláusula «quod facere potest» aplicam-se apenas no caso da sociedade universal. Na opinião de Guarino, Lenel, ao confrontar sua reconstituição com Ulp. 31 ed., D. 17, 2, 63 pr., deve ter imaginado que Sabino divergisse da orientação da fórmula edital, sustentando contrariamente que a actio pro socio e respectiva cláusula de condenação limitada pudessem ter aplicação fora da hipótese restrita da sociedade universal.

Guarino, discordando da tese de Lenel, considera que a condemnatio in id quod debitor facere potest tinha aplicação geral e cita, como prova disso, Pomp. 21 ad Q. Muc., D. 42, 1, 22, 1, no qual o jurisconsulto, discorrendo sobre a aplicação, causa cognita, do benefício, fala de socii em geral.

Em nossa opinião, porém, este argumento não parece tão-concludente como quer Guarino, pois o fato de Pompônio falar em socii não significa necessariamente que ele esteja se referindo a toda e qualquer espécie de sócio: em rigor, trata-se apenas de um plural, que pode estar fazendo referência aos sócios omnium bonorum, sem, porém, especificá-los, por considerar essa especificação desnecessária tendo em vista que a orientação dominante, como já mencionado, considerava que o benefício se aplicava apenas à sociedade universal. Por outro lado, não parece razoável basear num único fragmento toda a força de uma argumentação, quando se está a todo momento discutindo (nisso consiste o trabalho exegético dos romanistas) a autenticidade deles.

Finalizando seu raciocínio, Guarino parece concluir ${ }^{36}$ que o benefício teria sido estendido no período clássico aos sócios de toda e qualquer sociedade, sendo esta a opinião primeiro de Sabino e, depois, de Ulpiano. Nesse sentido, o fragmento recolhido em Ulp. $31 \mathrm{ed}$., D. 17, 2, 63 pr. seria, na essência, autêntico (embora reconhecendo-se nele algumas pequenas alterações formais) e a sua parte final («hoc enim...habeat») seria mesmo de autoria de Ulpiano, o qual teria encontrado no termo «quodammodo» o meio mais expressivo para evidenciar a analogia existente entre os socii (todos os socii, de qualquer espécie) e as pessoas ligadas por um vínculo de fraternidade, analogia esta que seria a mais apropriada

36. Dissemos parece porque, ao nosso ver, a sua conclusão, no meio de um emaranhado de digressões paralelas, não se torna clara (cf. La condanna..., cit. (nota 1), pp. 29-32.). 
para ilustrar a lógica, a ratio subjacente à condemnatio limitada de um sócio na ação proposta por outro.

Contudo, a opinião de Guarino deixa algumas questões sem uma explicação convincente. Entre outras esta: se no período clássico o benefício já se estendia a todos os sócios, o texto de Ulp. 63 ed., D. 42, 1, 16 deve reputar-se adulterado no período final (socium autem... accipiendum est). Mas, por quê razão um intérprete pós-clássico (e nem se fale do compilador justinianeu, em cuja época a aplicação do benefício já se estendia notoriamente a todos os tipos de sociedade) introduziria um comentário restritivo contrário à prática reinante? Se o período em questão tiver de ser considerado um glossema interpretativo, é mais razoável imaginar, como quer Arangio-Ruiz, ${ }^{37}$ tivesse ele o propósito de confirmar a orientação do edito (restrita no seu espírito à societas omnium bonorum, embora sem mencioná-la expressamente), saindo, assim, ao passo das opiniões contrárias daqueles que pretendiam ver o benefício estendido aos outros tipos de sociedade. Somente assim, prossegue Arangio-Ruiz, pode se entender a expressão «accipiendum est» que aparece no final do texto citado, pois o verbo accipere deixa transparecer a mão do intérprete, introduzindo interpretação restritiva que, no caso, não teria razão de ser se a menção às sociedades universais fosse explícita na própria fórmula.

A maioria dos autores julga, ${ }^{38}$ (e tal é a orientação que nos parece mais segura), que a condenação limitada foi introduzida para beneficiar apenas o sócio da societas omnium bonorum, sendo esta a orientação que permaneceu no direito clássico e pós-clássico, apesar de pressões esparsas no sentido de se ampliar sua aplicação. E, isto, por entender que só no caso da sociedade universal se caracterizaria de maneira plena aquela relação de especial confiança, o ius quodammodo fraternitatis, reminiscência do primitivo consortium fratrum suorum, confiança que justificaria a concessão do benefício, sendo esta a sua verdadeira ratio. Só na compilação justinianéia o instituto teria sido reformado, passando a valer para o sócio de toda e qualquer espécie de sociedade. É bom lembrar que estamos falando agora expressamente da condenação limitada e não da actio pro socio a qual, embora pudesse na origem ter sido criada, tendo em vista apenas a

37. Cf. La società..., cit. (nota 2), p. 30.

38. É esta a opinião taxativa de Levet, Le bénéfice..., cit. (nota 8), p. 56. Solazzi, L'estinzione..., cit. (nota 27), p. 207, considera-a a mais provável. Após afirmar que a restrição no antigo direito é clara, Arangio-Ruiz, La società..., cit. (nota 2), p.122, em relação ao direito clássico e pós-clássico, dá maior crédito, mas apenas conjecturalmente, à interpretação restritiva. 
societas omnium bonorum, passou entretanto desde fins da República a se aplicar aos diversos tipos de sociedade que foram surgindo.

Assim sendo, poderíamos reconstituir o beneficium competentiae do sócio da seguinte forma: após a introdução nos começos do séc. II a. C. da actio pro socio no edito do pretor urbano, ${ }^{39}$ teria sido introduzida em cláusula especial, ${ }^{40}$ provavelmente em fins do séc. II a. C. ou nas primeiras décadas do séc. I a. C., a condenação limitada em favor do sócio omnium bonorum, concedida pelo pretor causa cognita. ${ }^{41}$ Razão de ser deste tratamento diferenciado em favor do sócio universal, sua ratio, teria sido a existência de um vínculo de especial confiança, originando um ius quodammodo fraternitatis.

Parece, porém, razoável admitir, como quer Guarino, que desde o fim da República ou começo do Império alguns jurisconsultos defendessem a aplicação extensiva do benefício, chegando o assunto a motivar discussão entre eles. Sabino pode ter sido um dos partidários dessa corrente, assim como Ulpiano.

Pensamos, contudo, que isto não se pode taxativamente concluir a partir de Ulp. 31 ed., D. 17, 2, 63 pr., pois se, tal como querem alguns, considerarmos este texto interpolado pelo compilador, é possível admitir que a alteração tivesse atingido a opinião original de Sabino e de Ulpiano, e que na verdade fossem ambos favoráveis à aplicação restrita. Em tal caso, o teor original do fragmento de Ulpiano poderia ter sido «verum est quod Sabino videtur...si...universorum bonorum socii sunt,... in id quod facere possunt...», etc. ${ }^{42}$ Como se pode observar, a mudança deste texto original suposto para a redação que se encontra em Ulp. 31 ed., D. 17, 2, 63 pr. não parece muito complexa, tornando verossímil a hipótese de interpolação. O período final (hoc enim...habeat) pode ser considerado original de Ulpiano, como quer Guarino, ${ }^{43}$ ou mesmo, como opina Arangio-Ruiz, ${ }^{44}$ obra de comentarista pós-clássico, que o teria introduzido para

39. Na origem, de acordo com Lenel, Das Edictum..., cit. (nota 13), p. 297, e Arangio-Ruiz, La società..., cit. (nota 2), p. 31, aplicável apenas aos sócios da sociedade omnium bonorum. Mais tarde estendida aos demais tipos de sociedade.

40. Neste sentido, Arangio-Ruiz, La società..., cit. (nota 2), p.31, e também, Guarino, La condanna..., cit. (nota 1), pp. 30-31.

41. Lembramos Pomp. 21 ad Q. Muc., D. 42, 1, 22, 1.

42. Cf. Guarino, La condanna .., cit. (nota 1), p. 28.

43. Cf. La condanna..., cit. (nota 1), p. 32.

44. Cf. La società..., cit. (nota 2), p. 30. No mesmo sentido, Solazzi, L'estinzione..., cit. (nota 27), p. 207 e nota 1 . 
reforçar a aplicação restritiva do benefício, em decorrência desse especial relacionamento dos sócios universais (ius quodammodo fraternitatis), reagindo, assim, às pressões dos defensores de uma interpretação mais larga da condemnatio limitada.

$\mathrm{Na}$ perspectiva da aplicação restritiva do beneficium ao longo do direito clássico e pós-clássico podemos efetuar algumas leituras possíveis dos fragmentos de Ulpiano. Uma primeira, partindo da hipótese de que, concordando com a opinião de Sabino, Ulpiano acompanhasse a orientação dominante. ${ }^{45}$ Neste caso deveríamos considerar Ulp. 31 ed., D. 17, 2, 63 pr. interpolado e Ulp. 63 ed., D. $42,1,16$ original: Ulp. 31 ed., D. 17, 2, 63 pr. teria saído da pena de Ulpiano com a redação proposta supra («verum est quod Sabino videtur...si...universorum bonorum socii sunt,... in id quod facere possunt...»), e o teor original de Ulp. $63 \mathrm{ed}$, D. $42,1,16$ teria sido aquele mesmo que aparece nas fontes. Alterando o primeiro texto (Ulp. 31 ed., D. 17, 2, 63 pr.) e inserindo-o no lugar correspondente à actio pro socio, o compilador teria efetuado a reforma extensiva do instituto. ${ }^{46} \mathrm{Mas}$, em tal caso, por quê razão teria o compilador adulterado a opinião de Sabino e Ulpiano, conservando-lhes os nomes? É o que parece perguntar Guarino. ${ }^{47}$ Pensamos ser suficiente razão o desejo de se "dar força" à reforma extensiva, apresentando a "opinião" (adulterada) desses juristas como a ela favorável.

Pode-se, entretanto, imaginar -e é a segunda hipótese- que Sabino fosse favorável à aplicação extensiva do beneficio, mas não Ulpiano. É o que parece sugerir Arangio-Ruiz ${ }^{48}$ Nesse caso, Ulpiano teria escrito em 31 ed., D. 17, 2, 63 pr.: «verum non est...», ${ }^{49}$ estando tal redação em perfeita consonância com o afirmado em Ulp. 63 ed., D. 42, 1, 16. Ao utilizar o primeiro texto para seus propósitos de reforma, o compilador teria retirado dele a partícula non, tornando agora a opinião

45. Levet, Le bénéfice..., cit. (nota 8), p. 56, é desta opinião. Na nota 29 oferece uma possivel reconstituição do texto primitivo de Ulpiano (31 ed., D. 17, 2, 63 pr.: Verum est quod Sabino videtur $<<$ etiamsi non $>>$ universorum bonorum $<<$ socii $>>$ (socios, Ulpiano) $<<$ sunt, sed unius rei, attamen $>>$ in id quod facere possunt...condemnari oportere $<<$ hoc enim... habeat $>>$ ).

46. Deveriamos, contudo, admitir que, provavelmente por descuido, o compilador deixasse de adaptar à reforma o fragmento inserido em Ulp. $63 \mathrm{ed}$., D. 42, 1, 16. Esta falha, porém, poderia ser minimizada considerando-se que o livro 42 do Digesto não era o destinado como sede materiae a tratar propriamente da sociedade.

47. Cf. La condanna..., cit. (nota 1), p. 28

48. Cf. La società..., cit. (nota 2), p. 122.

49. Sobre esta possivel redação, embora com sentido diferente na argumentação do autor ( $a$ contrario), cf. Guarino, La condanna..., cit. (nota I), p. 28. 
de Ulpiano concordante com aquela de Sabino, ambas, portanto, em sintonia com a nova orientação.

Terceira hipótese consistiria, finalmente, em admitir que tanto Sabino quanto Ulpiano fossem contrários à limitação. Neste caso, Ulp. 31 ed., D. 17, 2, 63 pr. seria genuíno (ao menos nos seus traços gerais de conteúdo, deixando-se de lado as possíveis alterações no plano formal da redação), e como tal teria sido aproveitado pelo compilador para sacramentar a reforma extensiva. O texto de Ulp. 63 ed., D. 42, 1, 16, teria sofrido uma interpolação restritiva (o período «socium...accipiendum est»), obra de um comentarista pós-clássico, visando colocar o fragmento de Ulpiano em consonância com a orientação vigente, sendo inadvertidamente reproduzida, mais tarde, esta interpolação na compilação justinianéia sem a adaptação oportuna.

Abordada a questão relativa à espécie de sócio que gozaria do benefício, passemos agora a tratar de alguns outros problemas relacionados com este caso de condenação limitada.

O texto de Pompônio 21 ad Q. Muc., D. 42, 1, 22, 1, transcrito supra, afirma que o benefício da condenação limitada era concedido ao sócio somente causa cognita. Para Guarino ${ }^{50}$, esse exame in concreto permitia ao magistrado concluir pela existência ou não de boas razões para favorecer o réu.

De acordo com Pompônio, duas circunstâncias seriam levadas especialmente em consideração pelo pretor: o comportamento fraudulento daquele que falsamente negava sua condição de sócio e a existência de cláusula doli pela qual ele se obrigara.

A propósito da primeira delas, confirmada também num texto de Paulo 32 ed., D. 17, 2, 67, 3, ${ }^{51}$ Arangio-Ruiz comenta que a medida se justifica plenamente, pois, diz ele, "negar um contrato de sociedade existente é uma forma de defesa por demais inspirada na má-fé como para que aquele que a adota possa pretender um tratamento benigno". 52

A segunda circunstância causa um pouco de perplexidade. Com efeito, sendo a responsabilidade por dolo inerente aos contratos de boa-fé, entre os quais se conta a sociedade, a existência comprovada de dolo afastaria em qualquer caso a

50. Cf. La condanna..., cit. (nota 1), p. 25.

51. Non alias socius in id quod facere potest condemnatur, quam si confidetur se socium fuisse [O sócio é condenado ao que possa pagar somente se reconhece ter sido sócio].

52. Cf. La società..., cit. (nota 2), p. 184. 
aplicação do benefício, independentemente da existência de clausula dóli. ArangioRuiz, acompanhando a opinião de Levet, ${ }^{53}$ entende que esses textos fazem referência a uma sociedade, cuja convenção constitutiva tivesse sido feita mediante dupla estipulação. Não sendo a stipulatio um iudicium bonae fidei mas um contrato formal, a ocorrência de dolo somente poderia ser levada em consideração se convencionada mediante cláusula expressa.

Merece, finalmente, menção rápida a questão das consequiências desta espécie de condenação limitada. A este respeito, Arangio-Ruiz ${ }^{54}$ afirma que o sócio evitaria a execução pessoal ou a bonorum venditio mas, diferentemente de outros casos de concessão do benefício, não evitaria a infamia. Assim sendo, os efeitos do beneficium competentiae outorgado ao sócio seriam apenas patrimoniais. O mesmo autor observa que Juliano 1 dig., D. 3, 2, 1, ao enumerar as ações contratuais que acarretam infamia, cita em primeiro lugar a actio pro socio. E, a seguir, explica que a razão dessa severidade (mas também daquela indulgência em virtude da qual o benefício era concedido) encontra-se na fiducia, na confiança que devia ligar reciprocamente os sócios, confiança esta que tornava particularmente grave o fidem fallere, isto é, a violação da fides, da confiança mútua depositada.

São Paulo, dezembro de 1997.

53. Cf. La società..., cit. (nota 2), p. 184 e Le bénéfice..., cit. (nota 8), p. 59, respectivamente.

54. Cf. La società..., cit. (nota 2), pp. 185-6. 